\title{
Report from the Canadian Association of Gastroenterology Governing Board
}

\author{
William G Paterson MD FRCPC \\ President, Canadian Association of Gastroenterology \\ Department of Medicine, Queen's University, Kingston, Ontario
}

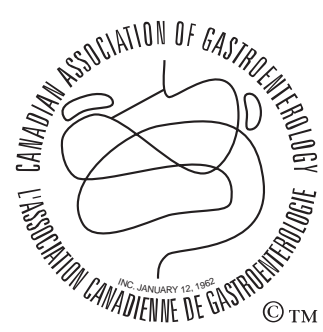

En français voir page 323
$\mathrm{T}_{\mathrm{c}}^{\mathrm{o}}$ o provide members with a view to the directions of the Canadian Association of Gastroenterology (CAG) Governing Board and its committees, we are pleased to introduce a short, at-a-glance summary in the form of the present News Page. Decisions and key initiatives from board meetings - held twice annually, in late autumn and in February at Canadian Digestive Diseases Week (CDDW) - will be presented. Here is a look at some of the projects currently underway:

\section{CLINICAL AFFAIRS}

Includes the Endoscopy, Hepatobiliary/Transplant, Liaison, Pediatrics, Practice Affairs and Regional Representation committees.

Endoscopy quality assurance initiative

As reviewed in the April News Page, the Governing Board has endorsed a pilot project on quality assurance in endoscopy, based on the United Kingdom program and the Global Rating Scale (www.grs.nhs.uk/).

\section{Credentialing papers}

Six manuscripts addressing credentialing related to esophagogastroduodenoscopy, sigmoidoscopy, colonoscopy, endoscopic retrograde cholangiopancreatography and endoscopic ultrasound, along with an introductory paper on general credentialing principles, are in the final stages and will be submitted for publication this year.

Consensus guidelines, position statements and background reviews

Three types of CAG publications have been agreed on and defined as follows: consensus guidelines, position statements (CAG opinion pieces about specific topics; one to two pages in length) and background reviews (reviews the relevant literature which may or may not accompany a position statement; similar to technical reviews by the American Gastroenterological Association).
Proton pump inhibitors and fractures - position statement Given questions from physicians and patients on the use of proton pump inhibitors and increased risk of hip fractures, a position statement by Drs Paul Moayyedi and Ann Cranney (Rheumatology \& Geriatric Medicine, University of Ottawa [Ottawa, Ontario]) is being prepared.

Sedation (propofol) - position statement

The Governing Board and Clinical Affairs support a position statement on sedation, with particular focus on propofol, which is to be developed over the coming weeks.

Primary care physician triage forms

The Practice Affairs committee is currently creating standard forms to guide family practitioners in referring patients for gastroenterology care.

\section{EDUCATION AFFAIRS}

Includes the Maintenance of Certification, Residents' Videoconference, the Gastroenterology Residents-in-Training (GRIT) course and the Scholars' Program, Program Directors and the Interactive Lecture Series committees.

\section{Planning for CDDW 2008}

Although the 2007 CDDW/3rd Annual CASL Winter Meeting was only a few weeks ago, planning for the 2008 conference is already underway. The 2008 CAG/CASL implementation committee will hold its first meeting in early May to review feedback from 2007 and set the template for the 2008 conference.

\section{Annual Education Affairs meeting}

Over the past year, Clinical Affairs has trialed a face-to-face meeting of its committee chairs, which has proved extremely successful as shown by the list of accomplishments above. Following this model, Education Affairs will meet with its committees in the spring of 2007 , to facilitate the many educational initiatives underway.

The CAG is proud to acknowledge its Benefactor Corporate Sponsors:

\begin{tabular}{|c|c|c|c|}
\hline Abbott Laboratories Lt & Nycomed (formerly ALTANA Pharma & AstraZeneca Canada Inc & Axcan Pharma Inc \\
\hline Janssen-Ortho Inc & Olympus Canada Inc & Procter \& Gamble Pharmaceuticals & Schering Canada Inc \\
\hline
\end{tabular}




\section{RESEARCH AFFAIRS}

CAG research applications - changes

Fellowships: Research applications will only be considered from trainees of supervisors who are regular CAG members or who are approved for provisional CAG regular member status. Individuals applying for fellowship training to be held at a non-Canadian centre will require sponsorship from a regular CAG member.

Grants: Research applications will only be considered from regular CAG members or investigators who have been approved for provisional regular CAG member status.

Applications for regular membership must be submitted to the CAG national office no later than July 1st for those submitting a research application for the October 15th deadline.

Increase in the value of the CAG summer studentships

The Governing Board has approved an increase in the value of the four CAG summer studentships, from $\$ 5,000$ to $\$ 6,000$ each ( $\$ 5,500$ salary plus $\$ 500$ grant), effective for the 2007 competition. This maintains the competitiveness of our awards with other grant bodies (eg, the Natural Sciences and Engineering Research Council of Canada).

\section{ADMINISTRATION}

New Web site - coming soon!

After the review of several proposals, a supplier has been hired to redesign the CAG Web site. Work begins in the spring of 2007, with the intent of launching the new Web site later in the year. In addition to a fresh look and easy navigation, the site will offer new functionality such as educational materials and online dues payment.

\section{Restructuring of the CAG Governing Board}

Restructuring of the CAG to meet changing needs of the membership and to streamline operations has been discussed in the January News Page and in February at the Annual General Meeting in Banff, Alberta. We invite members to provide their feedback (cagoffice@cag-acg.org) to help direct the future structure of the Association.

\section{Changes to disclosure guidelines for CAG members and speakers}

Given the increasingly stringent standards to ensure independence in continuing medical education activities, the ethics committee has updated the CAG disclosure form and is exploring potential changes to CAG educational events and activities. 


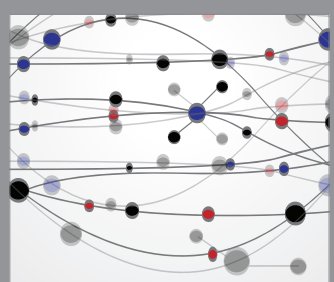

The Scientific World Journal
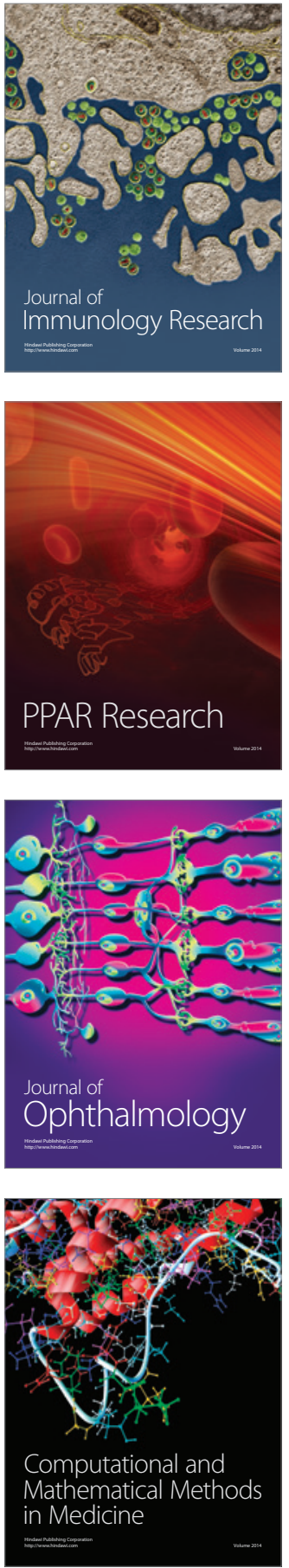

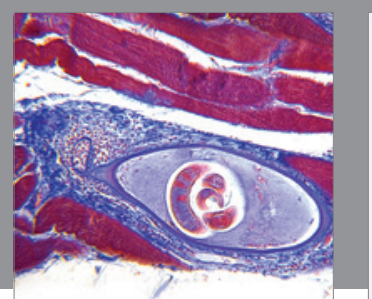

Gastroenterology Research and Practice

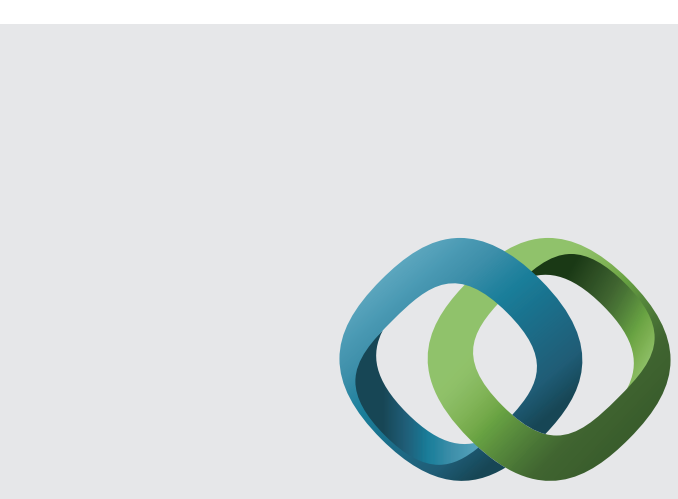

\section{Hindawi}

Submit your manuscripts at

http://www.hindawi.com
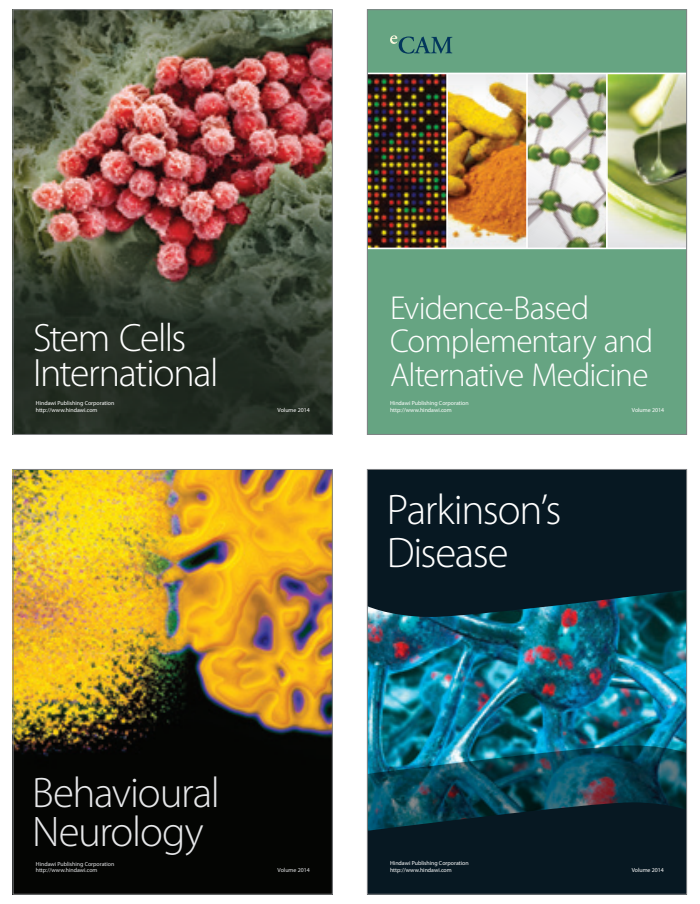
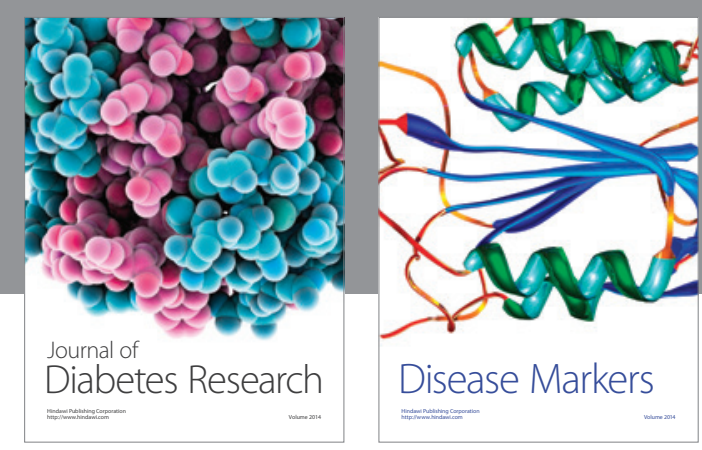

Disease Markers
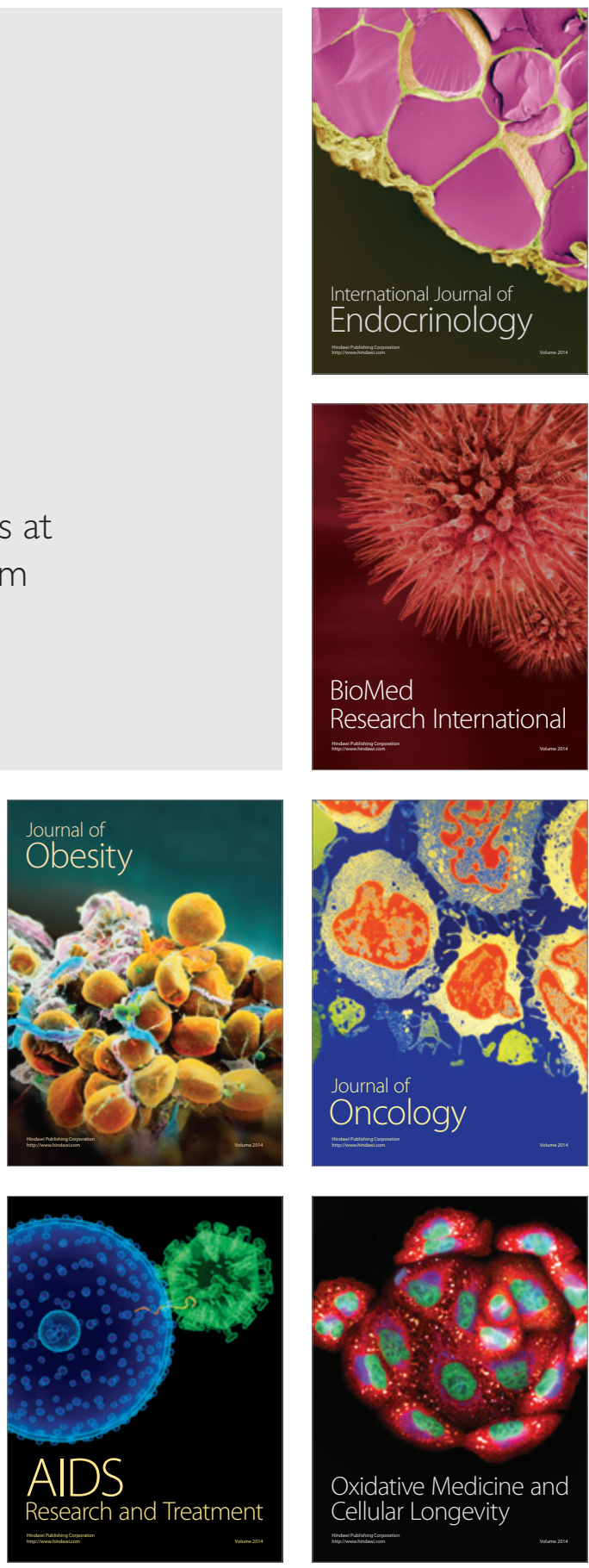